\title{
Description of Ghatiana, a new genus of freshwater crab, with two new species and a new species of Gubernatoriana (Crustacea: Decapoda: Brachyura: Gecarcinucidae) from the Western Ghat Mountains, India
}

\author{
S.K. Pati* and R.M. Sharma \\ Zoological Survey of India, Western Regional Centre, Pune, India
}

(Received 21 December 2012; accepted 22 October 2013; first published online 26 February 2014)

\begin{abstract}
A new genus of freshwater crab, Ghatiana, with two new species, Ghatiana aurantiaca and Ghatiana hyacintha, and a new species of Gubernatoriana Bott, 1970, are described from the Western Ghat Mountains in Maharashtra State, India. Ghatiana is most similar to Gubernatoriana by its wide, highly arched carapace and by the shape of the male abdomen. Nevertheless, the new genus can be distinguished from Gubernatoriana by the broadness of carapace, length of male abdomen, shape of sixth abdominal somite, length of telson and length of G1 terminal article. Ghatiana aurantiaca sp. nov. and G. hyacintha sp. nov. are distinguished by differences in body colour, carapace width, and G1 morphology, whereas Gubernatoriana triangulus sp. nov. is distinguished from two other known species [Gubernatoriana gubernatoris (Alcock, 1909) and Gubernatoriana pilosipes (Alcock, 1909)] by its triangular G1 subterminal segment and by its carapace morphology. Keys to the species of both the genera are provided.
\end{abstract}

\section{http://www.zoobank.org/urn:1sid:zoobank.org:pub:36BAA1EA-DC15-4B06- BA09-7BD26C63FF54}

Keywords: freshwater crabs; taxonomy; new genus; new species; India

\section{Introduction}

A systematic study of freshwater crab specimens from the Western Ghat Mountains in India (Figure 1) in the collection of the Zoological Survey of India (ZSI), Western Regional Centre (WRC), Pune, revealed two new species that belonged to a new genus, Ghatiana. Specimens were compared with species of Gubernatoriana Bott, 1970 [type species Paratelphusa (Globitelphusa) gubernatoris Alcock, 1909, by original designation; gender feminine], Inglethelphusa Bott, 1970 [type species Paratelphusa (Globitelphusa) fronto Alcock, 1909, by original designation and monotypy; gender feminine], Pilarta Bahir and Yeo, 2007 [type species Pilarta anuka Bahir and Yeo, 2007, by original designation and monotypy; gender feminine], Snaha Bahir and Yeo, 2007 [type species Snaha aruna Bahir and Yeo, 2007, by original designation; gender feminine] and Globitelphusa Alcock, 1909 [type species Paratelphusa (Globitelphusa) bakeri Alcock, 1909, by original designation; gender feminine]. The study also produced a new species of Gubernatoriana. Interestingly, all known species of Gubernatoriana and Inglethelphusa described by Alcock (1909) are from Mahabaleshwar in the Western Ghat Mountains.

*Corresponding author. Email: sameer_pati@yahoo.co.in 


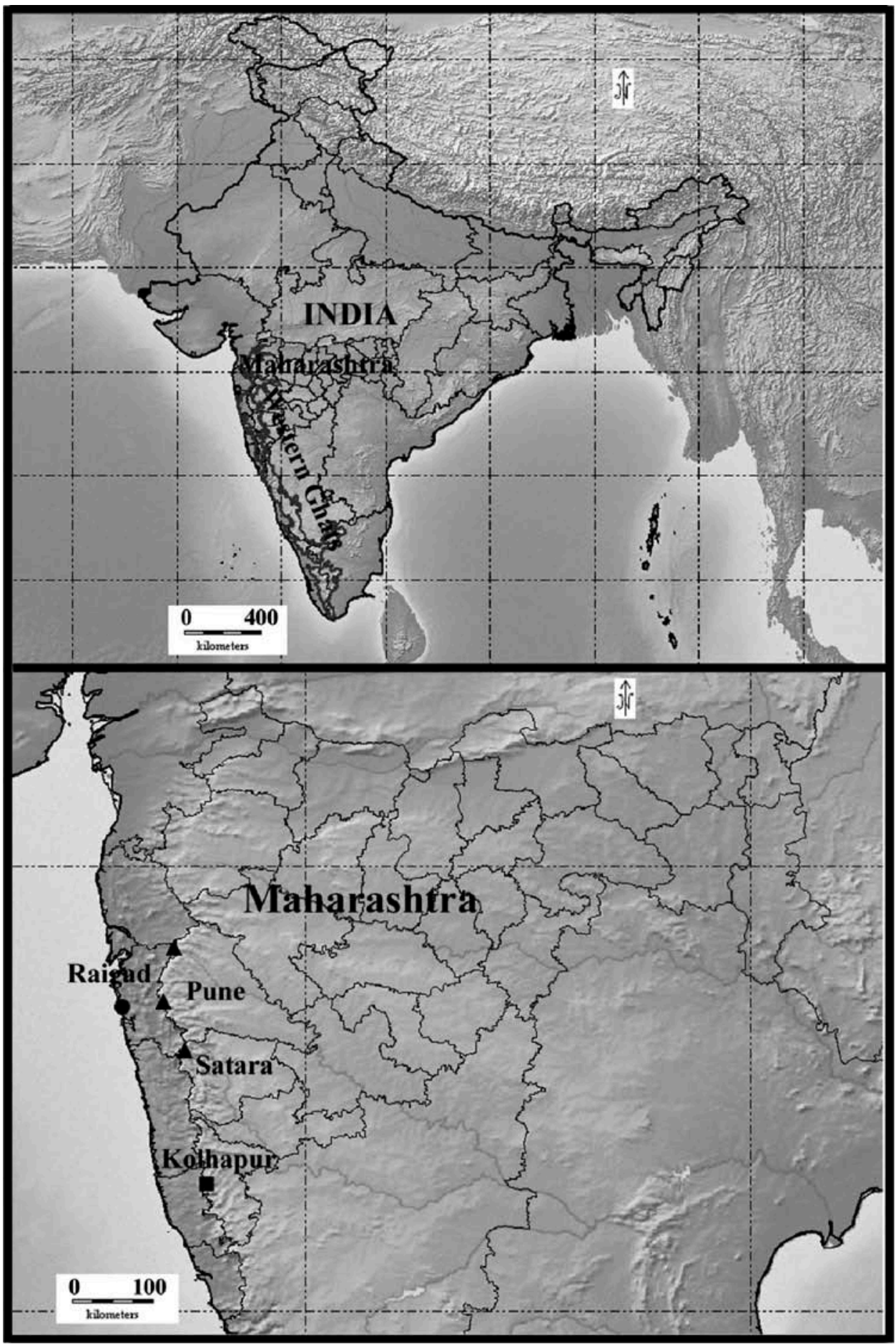

Figure 1. Map of collection sites of Ghatiana aurantiaca sp. nov. (circle); Ghatiana hyacintha sp. nov. (square) and Gubernatoriana triangulus sp. nov. (triangle). 
The measurements and terminology used follow $\mathrm{Ng}$ and Tay (2001) and Bahir and Yeo (2007). The following abbreviations are used: coll., collector; alt., altitude; cw, carapace width; cl, carapace length; ch, carapace height; fw, frontal width; s1, thoracic sternite $1 ; \mathrm{s} 2$, thoracic sternite $2 ; \mathrm{s} 3$, thoracic sternite $3 ; \mathrm{s} 4$, thoracic sternite $4 ; \mathrm{p} 2$, pereiopod 2; p3, pereiopod 3; p4, pereiopod 4; p5, pereiopod 5; G1, male first pleopod; G2, male second pleopod.

\section{Taxonomy}

Family GECARCINUCIDAE Rathbun, 1904

Ghatiana gen. nov.

Type species

Ghatiana aurantiaca sp. nov, by present designation.

\section{Diagnosis}

Carapace slightly broader than long (cl/cw $0.71-0.78$ ) (cw 1.3-1.4 times cl), highly arched (ch/cw 0.45-0.52), narrow posteriorly, ch more than 0.6 times cl; anterolateral margin short, slightly curved; front vertically deflexed, depressed, broad, nearly 0.4 times cw; epigastric crests distinct, low, broad, blunt; postorbital crests indistinct; external orbital angle poorly developed; epibranchial tooth indistinct, very close to level of supraorbital margin; cervical grooves poorly developed, interrupted; mesogastric groove long, deep, wide, extending into frontal region, bifurcate posteriorly; frontal median triangle incomplete with only dorsal margin; lacking epistomal median tooth (Figures 2A,B, 4A,B). Chelipeds unequal, carpal spine distinct, blunt, outer surface of merus rugose. Ambulatory legs with tuft of fine bristles. Suture between thoracic sternites s2/s3 indistinct and between s3/s4 incomplete visible as short grooves on sides only; s1, s2 with setae (Figures 2C, 3A, 4C, 5A). Male abdomen elongated, T-shaped; fifth abdominal somite broader than long; sixth abdominal somite longer than broad, but shorter than telson; telson long (Figures 3B, 5B); male sternoabdominal cavity deep, very long, extending beyond level of bases of third maxillipeds (Figures 2C, 4C). Exopods of first, second maxillipeds each with long flagellum; exopod of third maxilliped lacking flagellum, exopod longer than ischium (Figures 3D, 5D). G1 short with long terminal article (0.45-0.55 times length of subterminal segment); subterminal segment much broader than the terminal article (Figures 3E,F, 5E,F). G2 short with very short terminal article (Figures 3H, 5H).

\section{Etymology}

The genus name is derived from the word 'Ghat' because all the species in this genus are endemic to the Western Ghats. Gender feminine.

\section{Remarks}

Ghatiana, new genus, can be distinguished from other Indian gecarcinucid genera by the absence of a flagellum on the exopod of the third maxilliped (Figures 3D, 5D) 

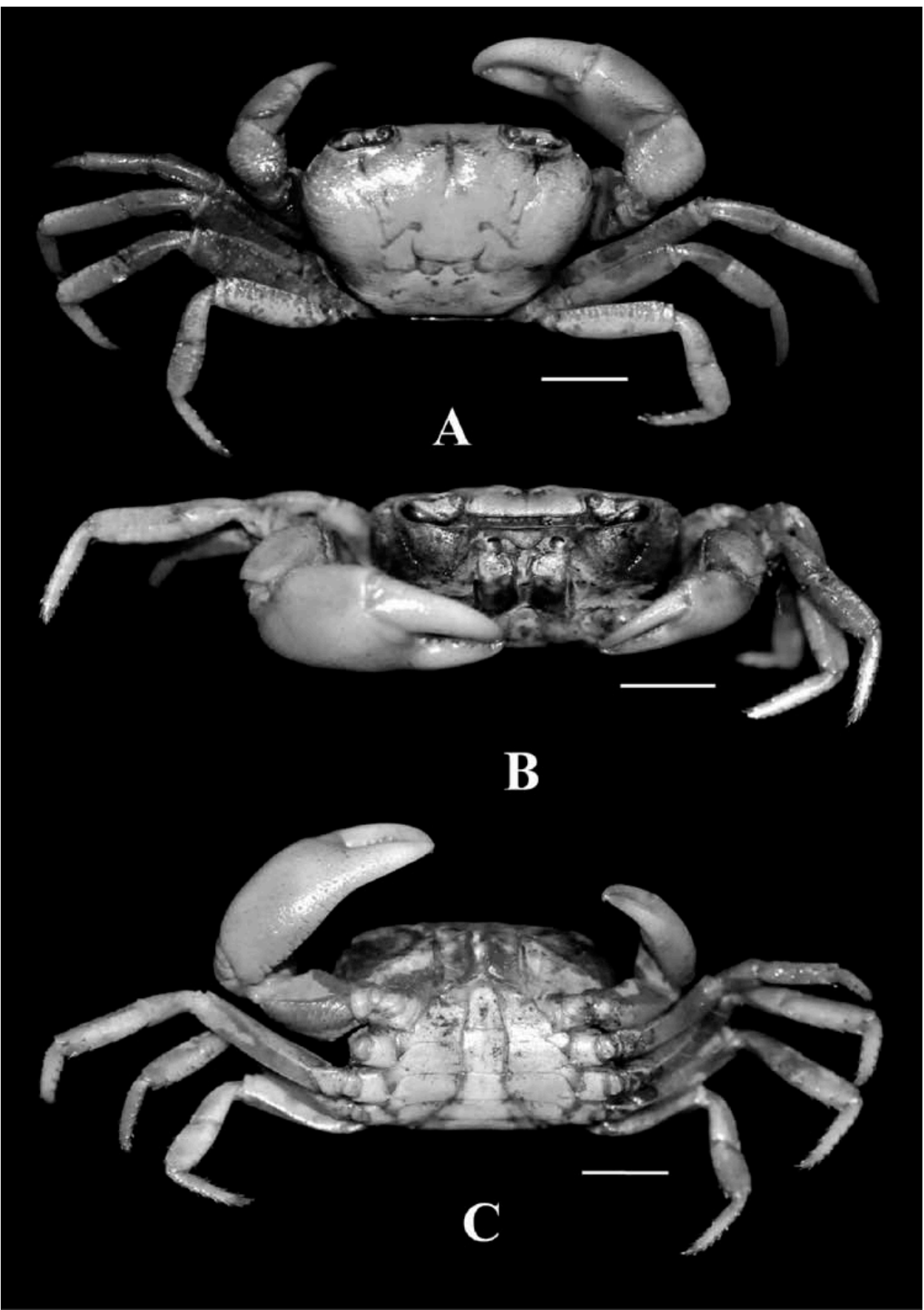

Figure 2. Ghatiana aurantiaca sp. nov., holotype male (ZSI, WRC-C.1129). (A) Dorsal view; (B) frontal view; (C) ventral view. Scale bars: $10 \mathrm{~mm}$. 

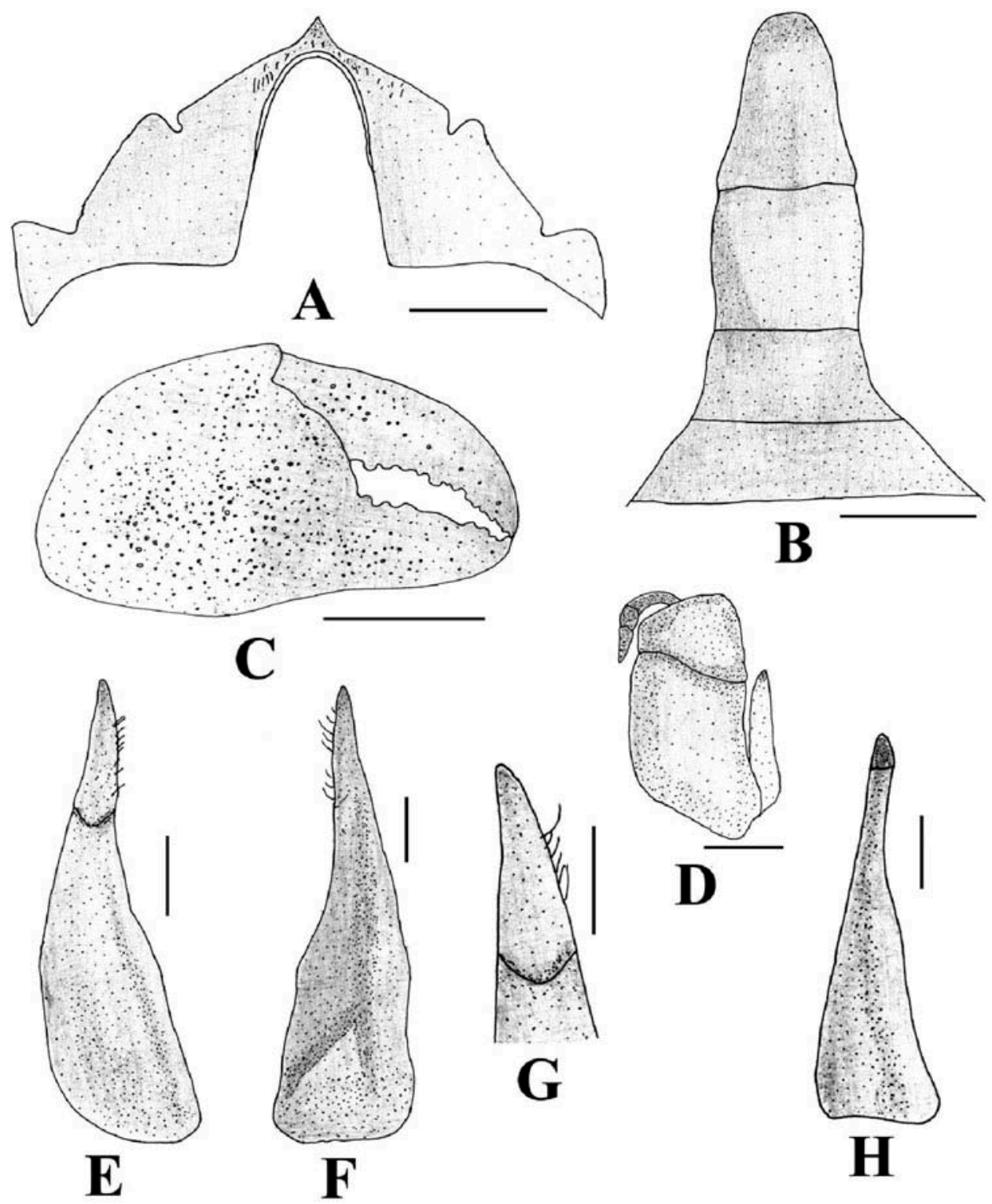

Figure 3. Ghatiana aurantiaca sp. nov., holotype male (ZSI, WRC-C.1129). (A) Anterior thoracic sternites; (B) abdomen; (C) right cheliped; (D) left third maxilliped; (E) dorsal view of right $\mathrm{G1}$; (F) ventral view of right $\mathrm{G} 1$; $(\mathrm{G})$ dorsal view of terminal article of right $\mathrm{G} 1$; (H) right $\mathrm{G} 2$. Scale bars: $5 \mathrm{~mm}(\mathrm{~A}, \mathrm{~B}) ; 10 \mathrm{~mm}(\mathrm{C}) ; 2.5 \mathrm{~mm}(\mathrm{D})$ and $1 \mathrm{~mm}$ $(\mathrm{E}-\mathrm{H})$.

(except Pilarta, Snaha, Globitelphusa, Inglethelphusa and Gubernatoriana, which possess a flagellum on this maxilliped).

The new genus is distinguished from Pilarta and Snaha by the G2 terminal article, which is very short (Figures 3H, 5H) (whereas Pilarta and 


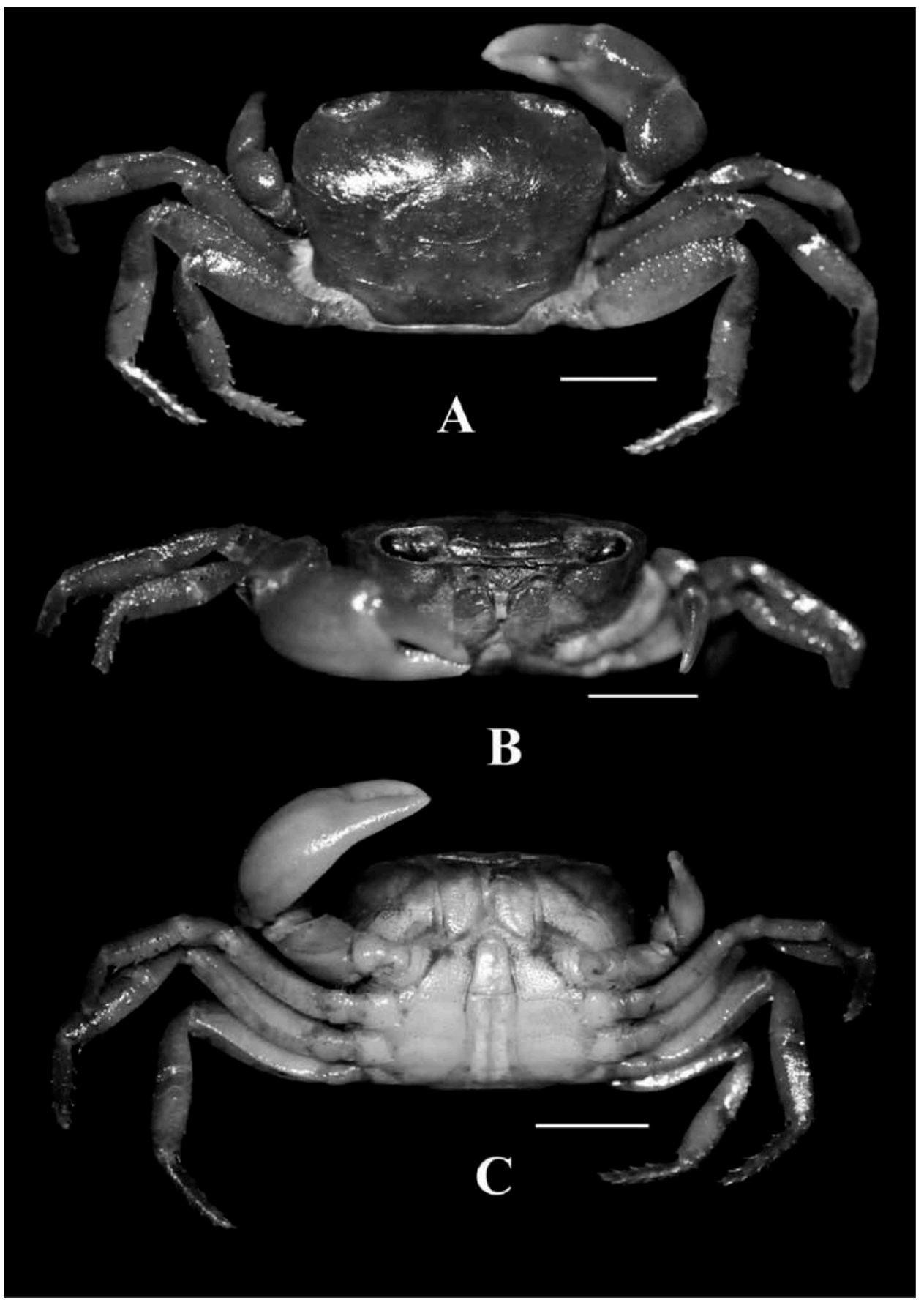

Figure 4. Ghatiana hyacintha sp. nov., holotype male (ZSI, WRC-C.1130). (A) Dorsal view; (B) frontal view; (C) ventral view. Scale bars: $10 \mathrm{~mm}$. 

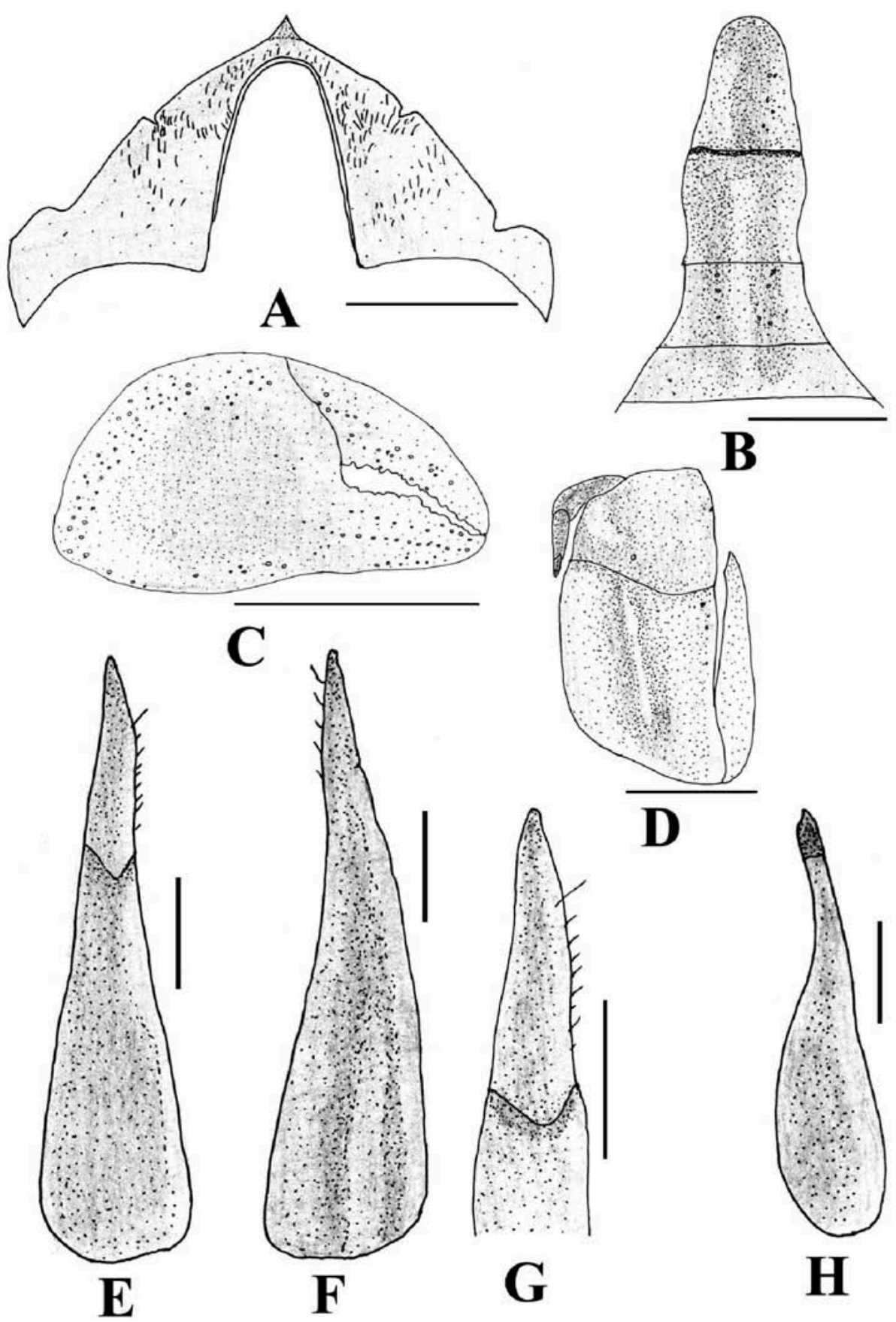

Figure 5. Ghatiana hyacintha sp. nov., holotype male (ZSI, WRC-C.1130). (A) Anterior thoracic sternites; (B) abdomen; (C) right cheliped; (D) left third maxilliped; (E) dorsal view of right $\mathrm{G} 1 ;(\mathrm{F})$ ventral view of right $\mathrm{G} 1 ;(\mathrm{G})$ dorsal view of terminal article of right $\mathrm{G1} ;(\mathrm{H})$ right G2. Scale bars: $5 \mathrm{~mm}(\mathrm{~A}, \mathrm{~B}) ; 10 \mathrm{~mm}(\mathrm{C}) ; 2.5 \mathrm{~mm}(\mathrm{D})$ and $1 \mathrm{~mm}(\mathrm{E}-\mathrm{H})$. 
Snaha have a flagellum-like G2 distal article) (Bahir and Yeo 2007: figs. 25H, 27G, 29E).

Ghatiana can be distinguished from Globitelphusa by the distal part of the subterminal segment of the G1: this is narrow, with an inner margin that gradually tapers without angulation in Ghatiana (Figures 3E,G, 5E,G) but broad with an inner margin that tapers sharply at an angle in Globitelphusa (Bott 1970: pl. 33, fig. 15). In addition, Globitelphusa is restricted to northeast India whereas Ghatiana is only found in the Western Ghats.

The new genus has some affinities with the monotypic genus Inglethelphusa in carapace morphology: both genera have a slightly curved anterolateral margin; very low, broad and blunt epigastric crests; a long mesogastric groove bifurcating posteriorly and extending into the frontal region; both lack an epistomal median tooth; both have an elongated and $\mathrm{T}$-shaped male abdomen; both have a long sixth male abdominal somite and long telson; both have a very long male sternoabdominal cavity extending beyond the level of the third maxilliped base, and a short G2 with a short terminal article. However, Ghatiana can easily be distinguished from Inglethelphusa by its broad carapace (cw/cl 1.3-1.4 vs 1.1), narrow frontal margin (fw/cw $0.38-0.41$ vs 0.46 ), long third maxilliped exopod that is longer than the ischium (vs a short third maxilliped exopod), and a short, slightly curved and stout G1 with a short terminal article (Figures 2A,B, 3D-F, 4A,B, 5D-F) (vs a long, almost straight, narrow G1 with a very long terminal article) (Bott 1970: pl. 34, figs. 25-28).

The G1s of Ghatiana and Gubernatoriana appear superficially similar but the terminal article of the former is longer than that of the latter (Figures 3E, 5E, 7E; Bott 1970: pl. 27, fig. 27; pl. 34, fig. 36). Further, Ghatiana can be differentiated from Gubernatoriana by its broad and highly arched carapace (vs squarish and comparatively less arched carapace), elongated $\mathrm{T}$-shaped male abdomen with sixth male abdominal somite longer than broad and a long telson (vs short T-shaped male abdomen with sixth male abdominal somite slightly broader than long and a short telson) (Figures 2A,C, 3B, 4A,C, 5B, 6 A,C, 7 B; Bott 1970: pl. 6, figs. 61, 62; pl. 34, figs. 33,34$)$.

\section{Ecological notes}

Specimens were found in burrows dug into the banks of small streams, or under small stones, or inside cavities of laterite boulders on land or in holes in tree trunks. These crabs were especially active during the night in the rainy season where they were found either walking on the ground or on laterite boulders or climbing up tree trunks (Pati and Sharma, unpublished data).

\section{Distribution}

Northern Western Ghat Mountains, India. The type species was found in laterite regions of Konkan (244 $\mathrm{m}$ above sea level) whereas the other species was recorded from elevated Ghat areas ( $883 \mathrm{~m}$ above sea level).

Two species are included in Ghatiana gen. nov.: Ghatiana aurantiaca sp. nov. (type species) and Ghatiana hyacintha sp. nov. 


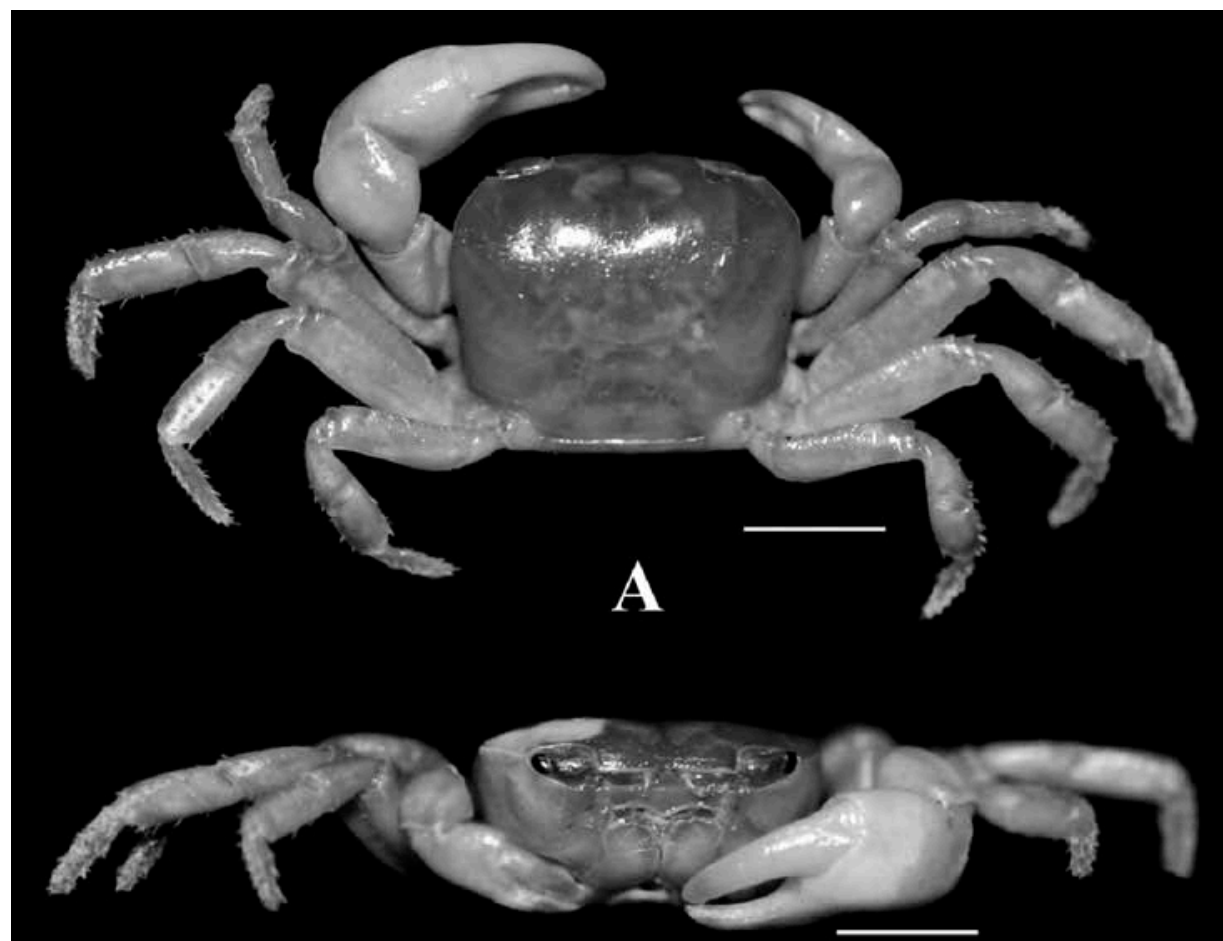

B

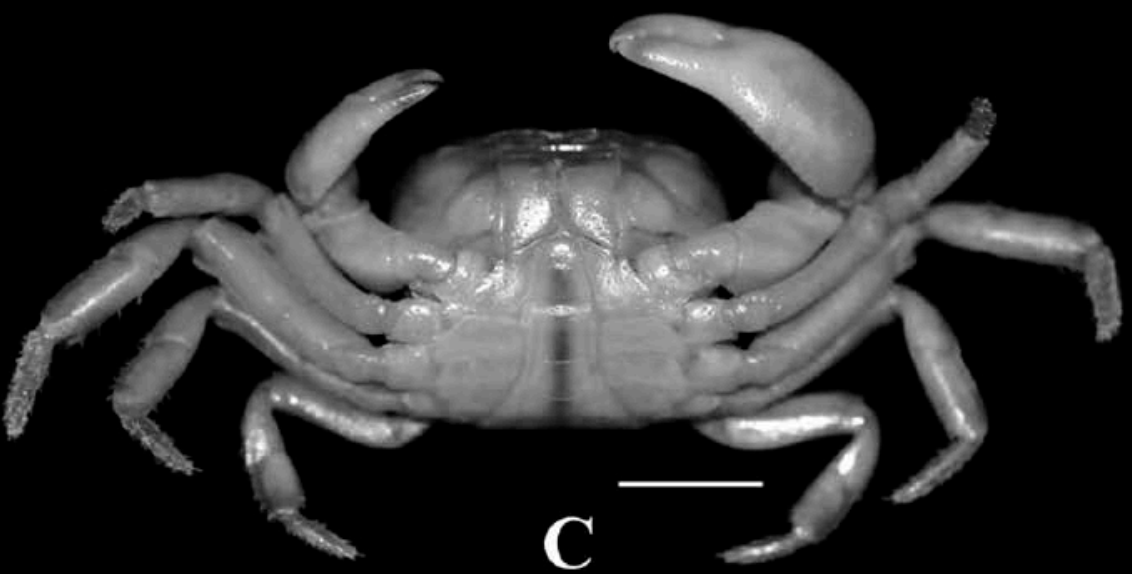

Figure 6. Gubernatoriana triangulus sp. nov., holotype male (ZSI, WRC-C.1134). (A) Dorsal view; (B) frontal view; (C) ventral view. Scale bars: $10 \mathrm{~mm}$. 

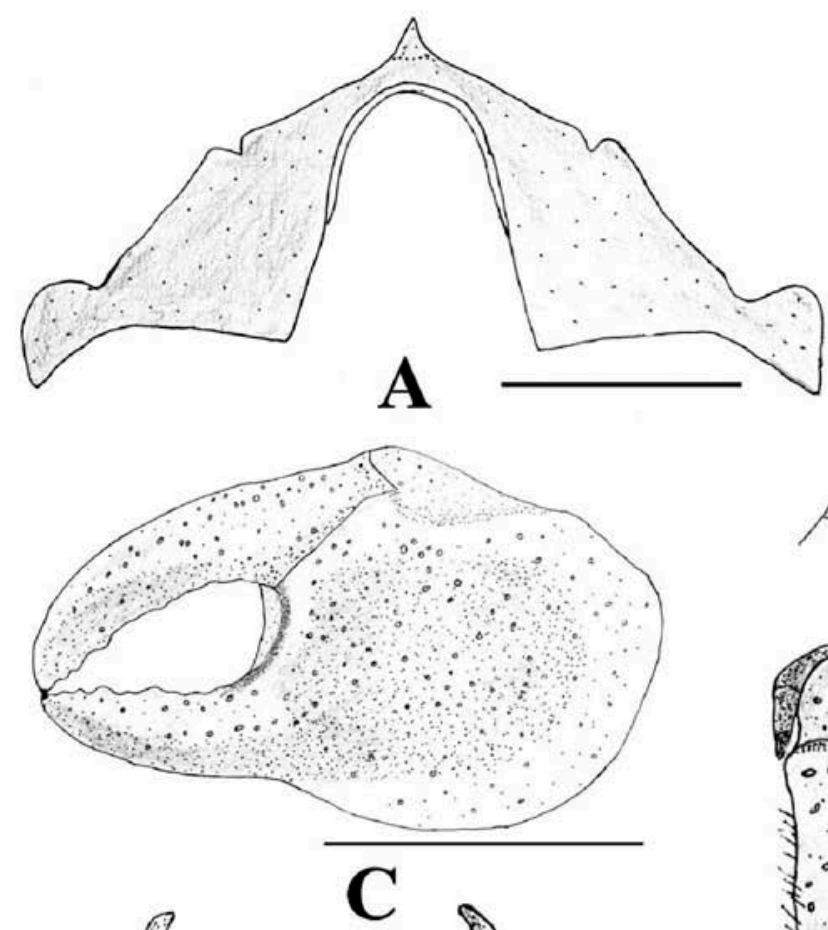

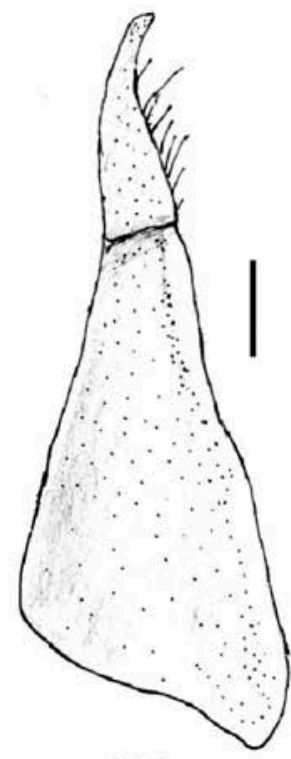

$\mathbf{E}$
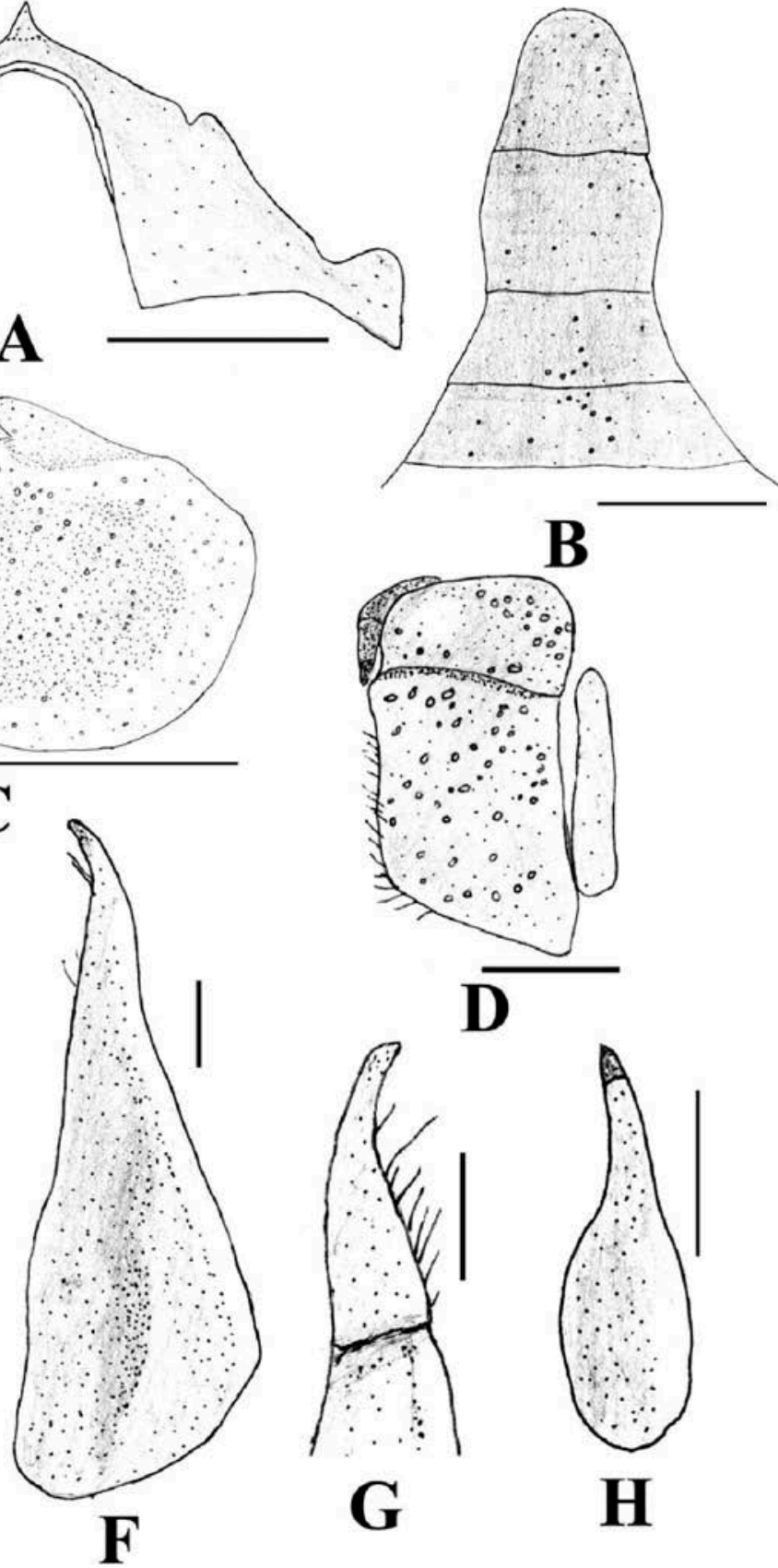

B
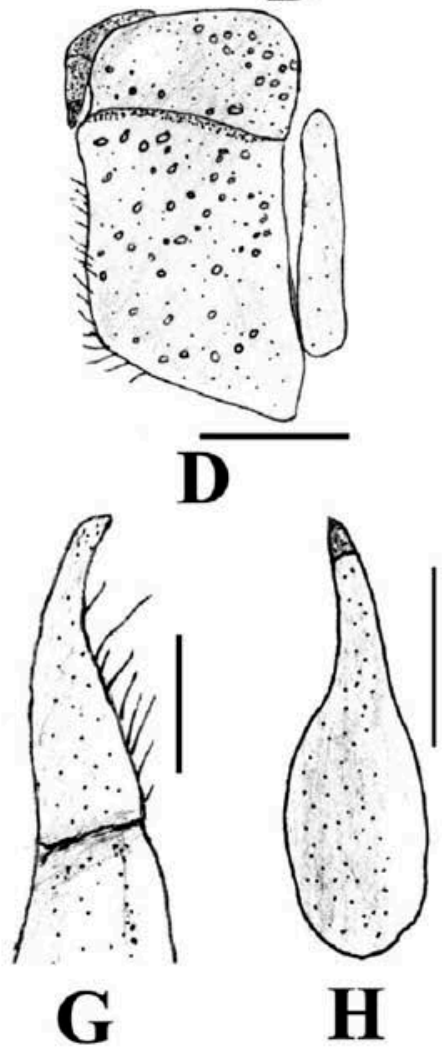

Figure 7. Gubernatoriana triangulus sp. nov., holotype male (ZSI, WRC-C.1134). (A) Anterior thoracic sternites; (B) abdomen; (C) left cheliped; (D) left third maxilliped; (E) dorsal view of right $\mathrm{G} 1$; $(\mathrm{F})$ ventral view of right $\mathrm{G} 1 ;(\mathrm{G})$ dorsal view of terminal article of right $\mathrm{G} 1 ; \mathrm{H})$ right G2. Scale bars: $5 \mathrm{~mm}(\mathrm{~A}, \mathrm{~B}) ; 10 \mathrm{~mm}(\mathrm{C}) ; 2.5 \mathrm{~mm}(\mathrm{D})$ and $1 \mathrm{~mm}(\mathrm{E}-\mathrm{H})$. 
Ghatiana aurantiaca sp. nov.

(Figures 2A-C, 3A-H, 8 A)

\section{Type specimens}

Holotype: male (cw $17.10 \mathrm{~mm}$, cl $12.14 \mathrm{~mm}$, ch $7.76 \mathrm{~mm}$, fw $6.42 \mathrm{~mm}$ ), coll. P.S. Bhatnagar and party (ZSI, WRC-C.1129), Forest Rest House, Phansad Wildlife Sanctuary, Raigad district, Maharashtra, India, $18^{\circ} 25^{\prime} 27.912^{\prime \prime} \mathrm{N}, 72^{\circ} 56^{\prime} 53.1672^{\prime \prime} \mathrm{E}$, alt. $244 \mathrm{~m}$; paratypes: 2 males (cw $14.52-15.64 \mathrm{~mm}$, cl $10.64-11.30 \mathrm{~mm}$, ch 6.84 $7.30 \mathrm{~mm}$, fw 5.64-6.04 mm) and 2 females (cw 10.94-15.64 mm, cl 7.94-11.12 mm, ch 4.70-7.26 mm, fw 4.30-6.00 mm) (ZSI, WRC-C.828), same data as holotype.

\section{Diagnosis}

Carapace slightly broader than long $(\mathrm{cl} / \mathrm{cw}=0.71-0.73)$; anterolateral margin curved with smooth, cristiform, thick, oblique striations; epigastric crests distinct, low, broad, blunt; postorbital crests indistinct; epibranchial tooth indistinct; mesogastric groove long, deep, extending into frontal region up to frontal margin; frontal median triangle incomplete with only dorsal margin; epistomal median lobe broadly triangular with rounded apex, lacking median tooth (Figure 2A,B). Suture between thoracic sternites s2/s3 indistinct and between s3/s4 visible as grooves on sides only; s1, s2 with bunch of setae (Figures 2C, 3A). Male abdomen elongated T-shape; fifth abdominal somite broader than long; sixth abdominal somite longer than broad; telson longer than sixth abdominal somite (Figures 2C, 3B). G1 short, slightly curved outward with long terminal article ( 0.45 times length of subterminal segment); tip pointed; subterminal segment much broader than terminal article, basal two-thirds much broader than distal one-third (Figure 3E-G). G2 short with very short or vestigial terminal article (Figure $3 \mathrm{H}$ ). Carapace orange red in living animals (Figure 8A).

\section{Description}

Carapace slightly broader than long (cw/cl 1.4), narrow posteriorly; highly arched $(\mathrm{ch} / \mathrm{cl}$ 0.64), anterolateral carapace inflated in frontal view; dorsal carapace surface rugose on lateral sides; anterolateral margin curved with smooth, cristiform, thick, oblique striations; posterolateral margin with fine, oblique striations; front depressed, vertically deflexed, broad, fw/cw 0.4 ; frontal margin slightly undulating; epigastric crests distinct, low, broad, blunt; postorbital crests indistinct; external orbital angle poorly developed; epibranchial tooth indistinct, very close to level of supraorbital margin; postorbital region slightly deep; branchial regions inflated, rugose; subhepatic region with fine striations; cervical grooves poorly developed, interrupted; mesogastric groove long, deep, extending to frontal margin, bifurcated posteriorly; H-groove visible; frontal median triangle incomplete with only dorsal margin; epistomal median lobe broadly triangular with rounded apex, lacking median tooth (Figure 2A,B).

Chelipeds unequal; right chela much larger; smooth; teeth on fingers blunt, almost of equal size; dactylus shorter than palm; fingers of larger chela meet only at tip (Figure 3C); carpal spine distinct, blunt; carpus devoid of bristles; outer surface of merus rugose. 

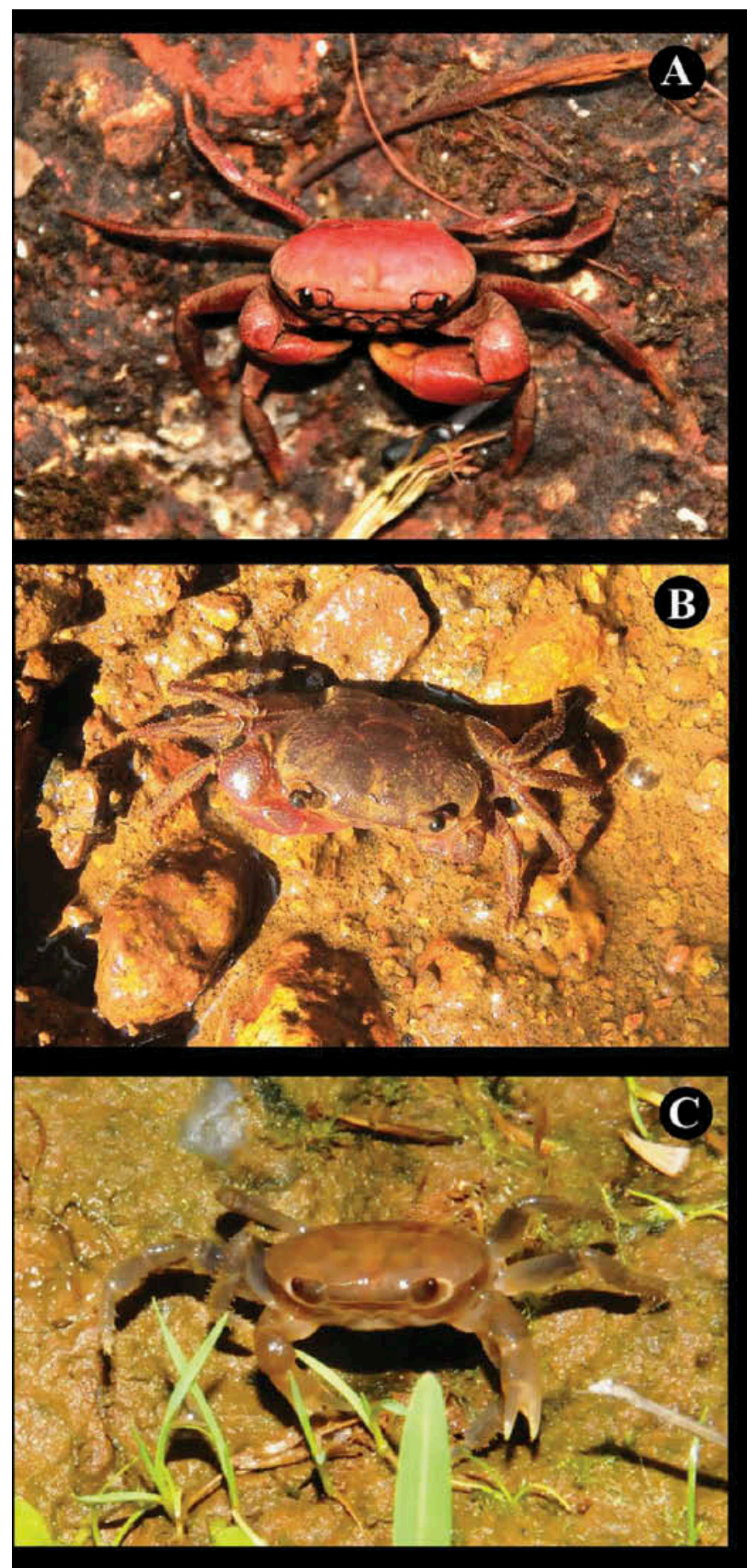

Figure 8. Newly described crabs from their natural habitats. (A) Ghatiana aurantiaca sp. nov., from laterite rocks in Phansad Wildlife Sanctuary, Raigad district; (B) Ghatiana hyacintha sp. nov., from bank of a stream in Radhanagari Wildlife Sanctuary, Kolhapur district; (C) Gubernatoriana triangulus sp. nov., from bank of a stream in Tahmini Ghat, Pune district. 
Ambulatory legs (p2-p5) long with very fine, small tuft of brownish bristles with yellowish tips mostly on margins; dactylus (p4 and p5) longer than propodus; longest propodus (p3) three times as long as broad.

Suture between thoracic sternites s2/s 3 indistinct, suture between sternites s3/s4 missing except for two short lateral grooves; s1, s2 heavily setose (Figures $2 \mathrm{C}, 3 \mathrm{~A})$.

Male abdomen elongated, T-shaped; fifth abdominal somite broader than long with concave lateral margins, distal width shorter than proximal width; sixth abdominal somite longer than broad, shorter than telson with slightly convex lateral margins, proximal width equal to distal width; telson elongated, broadly rounded at apex (Figures 2C, 3B); male sternoabdominal cavity deep, very long, extending much beyond level of bases of third maxillipeds (Figure 2C).

Exopod of first, second maxillipeds with long flagellum; exopod of third maxilliped lacking flagellum, longer than ischium, ventral sulcus on ischium indistinct, merus quadrangular, anterior external angle of merus right angled, slightly depressed (Figure 3D). Mandibular palp with two joints, terminal joint bilobed.

G1 short, slightly curved outward with long terminal article ( 0.45 times length of subterminal segment); terminal article narrower than subterminal segment, tip pointed; subterminal segment broader than terminal article, basal two-thirds broader than distal third (Figure 3E-G). G2 short with very short or vestigial terminal article; proximal half of basal segment distinctly broader than distal half (Figure $3 \mathrm{H}$ ).

\section{Colour}

Live animals have an orange-red carapace and chelipeds (Figure 8A); specimens preserved in ethanol have a yellow-brown carapace and chelipeds.

\section{Etymology}

The specific epithet derived from the Latin word aurantiacus meaning 'orange-red', refers to the orange-red colour of the live crab.

\section{Remarks}

Ghatiana aurantiaca sp. nov. is similar to G. hyacintha sp. nov. in general carapace morphology and G1 structure. However, these two species are clearly differentiated by the following characters: orange-red colour when alive (vs violet when alive); carapace more transversely elongate in appearance, cw/cl 1.4 (vs carapace less transverse and more squarish in appearance, cw/cl 1.3); epistomal median lobe broadly triangular with rounded apex (vs epistomal median lobe broadly triangular with slightly acute apex); thoracic sternites s3/s4 smooth, lacking setae (vs sternites s3/s4 highly setose); short G1 terminal article 0.45 times length of subterminal segment (vs long terminal article 0.55 times length of subterminal segment); basal two-thirds of G1 subterminal segment broader than distal one-third (vs basal half of G1 subterminal segment broader than distal half) (Figures 2A,B, 3A,E, 4A, B, 5A,E, 8A,B). 


\section{Ecological notes}

Ghatiana aurantiaca lives on land inside cavities of laterite boulders, and inside holes in tree trunks (present study). This crab species is active during the night in the rainy season when it is often seen walking on the ground, on laterite boulders, or climbing up tree trunks (Pati and Sharma, unpublished data).

\section{Distribution}

Known only from the type locality.

Ghatiana hyacintha sp. nov.

(Figures 4A-C, 5A-H, 8B)

\section{Type specimens}

Holotype: male (cw $13.58 \mathrm{~mm}$, cl $10.54 \mathrm{~mm}$, ch $6.62 \mathrm{~mm}$, fw $5.60 \mathrm{~mm}$ ), coll. S.S. Jadhav and party (ZSI, WRC-C.1130), Mahadeb Mandir, Radhanagari Wildlife Sanctuary, Kolhapur district, Maharashtra, India, 16²5'24.2796" N, 7354'7.1964" E, alt. $883 \mathrm{~m}$; paratypes: 3 males (cw 12.36-13.42 mm, cl 9.56-10.24 mm, ch 6.06$6.54 \mathrm{~mm}$, fw 5.16-5.66 mm) and 2 females (cw 12.02-13.80 mm, cl 9.20-10.50 mm, ch 6.22-6.64 mm, fw 5.04-5.84 mm) (ZSI, WRC-C.825), same data as holotype.

\section{Diagnosis}

Carapace broader than long ( $\mathrm{cl} / \mathrm{cw}$ 0.76-0.78); anterolateral margin curved with finely serrated crest curving into branchial regions, short, oblique, distinct striations on lateral sides; epigastric crests distinct, low, broad, blunt; postorbital crests indistinct; epibranchial tooth indistinct; mesogastric groove long, deep, wide, extending into frontal region; frontal median triangle incomplete with only dorsal margin; epistomal median lobe broadly triangular with slightly acute apex, lacking median tooth (Figure 4A,B). Suture between thoracic sternites s2/s3 indistinct, suture between s3/s4 incomplete except for short lateral grooves; s1-s4 with setae spreading uniformly (Figures 4C, 5A). Male abdomen elongated T-shape; fifth abdominal somite broader than long; sixth abdominal somite longer than broad; telson longer than sixth abdominal somite (Figures 4C, 5B). G1 short, slightly curved outward with long terminal article (0.55 times length of subterminal segment); tip pointed; subterminal segment comparatively much broader than terminal article, basal half much broader than distal half (Figure 5E-G). G2 short with very short or vestigial terminal article (Figure 5H). Living specimens with violet carapace and legs (Figure 8B).

\section{Description}

Carapace slightly broader than long (cw/cl 1.3), narrow posteriorly, highly arched (ch/cl 0.63), anterolateral carapace inflated in frontal view; anterolateral margin curved with a very finely serrated crest curving into branchial regions, short, oblique, distinct striations on lateral sides; posterolateral margin with short, distinct, oblique striations; front slightly depressed in middle, vertically deflexed, broad, fw/cw 0.4; 
frontal margin nearly straight; epigastric crests distinct, low, broad, blunt; postorbital crests indistinct; external orbital angle poorly developed; epibranchial tooth indistinct, very close to level of supraorbital margin; postorbital region shallow; branchial regions inflated, rugose; subhepatic region with fine striations; cervical grooves poorly developed, interrupted; mesogastric groove long, deep, wide, extending into frontal region, bifurcate posteriorly; H-groove visible; frontal median triangle incomplete with only dorsal margin; epistomal median lobe broadly triangular with slightly acute apex, lacking distinct median tooth (Figure 4A,B).

Chelipeds unequal; right chela larger; smooth; fingers of major cheliped with two or three larger teeth, fingers meeting only at tip; dactylus of major cheliped shorter than palm (Figure 5C); carpus with large blunt tooth; carpus almost devoid of bristles; outer surface of merus rugose.

Ambulatory legs (p2-p5) long with very fine, small, tuft of two or three brownish bristles with yellowish tips mostly on margins; dactylus (p4 and p5) longer than propodus; longest propodus (p4) three times as long as broad.

Suture between thoracic sternites s2/s3 indistinct, suture between s3/s4 missing except for two lateral grooves; s1-s4 with setae spreading uniformly (Figures 4C, 5A).

Male abdomen elongated, T-shaped; fifth abdominal somite broader than long with concave lateral margins, distal width shorter than proximal width; sixth abdominal somite longer than broad, shorter than telson with convex lateral margins, proximal width equal to distal width; telson elongated, broadly rounded at apex (Figures 4C, 5B); male sternoabdominal cavity deep, very long, extending much beyond level of third maxilliped bases (Figure 4C).

Exopod of first and second maxillipeds with long flagellum; exopod of third maxilliped lacking flagellum, longer than ischium; ventral sulcus on ischium shallow, towards centre; merus quadrangular, anterior external angle of merus right angled, slightly depressed (Figure 5D). Mandibular palp with two joints, terminal joint bilobed.

G1 short, slightly curved outward with long terminal article ( 0.55 times length of subterminal segment); terminal article narrower than subterminal segment, tip pointed; subterminal segment broader than terminal article, basal half broader than distal half (Figure 5E-G). G2 short with very short or vestigial terminal article; proximal half of basal segment distinctly broader than distal half (Figure $5 \mathrm{H}$ ).

\section{Colour}

Live animals have a violet carapace and chelipeds (Figure 8B); specimens preserved in ethanol have a dark brown carapace and faint violet chelipeds.

\section{Etymology}

The specific epithet, hyacintha alludes to the violet colour of the species with reference to the colour of the flowers of water hyacinth.

\section{Remarks}

Ghatiana hyacintha is similar to G. aurantiaca in overall carapace morphology and G1 structure. Nevertheless, the species can be distinguished by the colouration of the carapace, relative width of the carapace, appearance of the apex of the epistomal 
median lobe, pattern of the setae on thoracic sternites, and relative length of G1 terminal article and relative broadness of G1subterminal segment. For differences see Remarks for $G$. aurantiaca.

\section{Ecological notes}

Specimens were collected from burrows of the banks of small streams, and from under small stones. These crabs are generally more active during the rainy season (from June to September) (Pati and Sharma, unpublished data).

\section{Distribution}

Known only from the type locality.

\section{Key to the species of Ghatiana}

1. Carapace of living specimens orange-red; wide (cl/cw $0.71-0.73$ ); epistomal median lobe semicircular; thoracic sternites 3 and 4 smooth, lacking setae. G1 terminal article 0.45 times length of subterminal segment; basal twothirds of subterminal segment much broader than distal third

Ghatiana aurantiaca sp. nov.

Carapace of living specimens violet; not widened (cl/cw 0.76-0.78); epistomal median lobe broadly triangular; thoracic sternites 3 and 4 setose. G1 terminal article 0.55 times length of subterminal segment; basal half of subterminal segment much broader than distal half Ghatiana hyacintha sp. nov.

Gubernatoriana Bott, 1970

Paratelphusa (Globitelphusa) Alcock, 1909; 1910: 117 (part) (not Paratelphusa (Globitelphusa) Alcock, 1909).

Gubernatoriana Bott, 1970: 44.

Gubernatoriana Bahir and Yeo, 2007: 334.

Gubernatoriana $\mathrm{Ng}$ et al. 2008: 67.

Type species

Paratelphusa (Globitelphusa) gubernatoris Alcock, 1909, by original designation.

\section{Diagnosis (revised after Bott 1970; based on type species and present material)}

Carapace squarish (cl/cw 0.78-0.92) (cw 1.1-1.3 times cl), flat (ch/cl 0.6); anterolateral margin short, nearly straight; front vertically deflexed, narrow (fw/cw $0.35-0.42$ ); epigastric crests slightly developed; postorbital crests indistinct; external orbital angle poorly developed; epibranchial tooth indistinct; cervical grooves indistinct; mesogastric groove long, without bifurcation posteriorly; frontal median triangle incomplete with only dorsal margin visible; epistomal median lobe broadly triangular, lacking median tooth (Figure 6A,B; Bott 1970: pl. 6, figs 60, 61; pl. 34, figs 33, 35). Chelipeds unequal. 
Ambulatory legs with fine bristles. Suture between thoracic sternites s $2 / \mathrm{s} 3$ indistinct or visible as a small groove and between s3/s4 visible as grooves on sides only (Figures 6C, 7A; Bott 1970: pl. 6, fig. 62; pl. 34, fig. 34). Male abdomen short T-shaped; fifth abdominal somite much broader than long; sixth abdominal somite slightly broader than long, subequal in length to telson; telson short; male sternoabdominal cavity deep, long, extending beyond level of cheliped bases or even beyond level of third maxilliped bases (Figures 6C, 7B; Bott 1970: pl. 6, fig. 62; pl. 34, fig. 34). Exopods of first, second maxillipeds with long flagellum; exopod of third maxilliped lacking flagellum, exopod longer than ischium (Figure 7D). G1 short, stout with long terminal article (0.35-0.50 times length of subterminal segment); subterminal segment much broader than terminal article (Figure 7E-G; see Bott 1970: pl. 27, fig. 27; pl. 34, fig. 36). G2 short with very short or vestigial terminal article (Figure $7 \mathrm{H})$.

\section{Remarks}

Gubernatoriana is morphologically close to Ghatiana, new genus, but can be differentiated based on some significant external morphological characters (see Remarks for Ghatiana). This genus is distinguished from Snaha and Pilarta by the short terminal article of G2 (Figure 7H) (vs long terminal article of G2) (Bahir and Yeo 2007: figs. 25H, 27G, 29E). Gubernatoriana is distinguished from Inglethelphusa by the long third maxilliped exopod and short, stout G1 (vs short third maxilliped exopod and long, narrow G1) (Figure 7D-F; Bott 1970: pl. 34, figs. 26, 28). Gubernatoriana escheri (Roux, 1931) was recently assigned to the genus Snaha, while Gubernatoriana nilgiriensis (Roux, 1931) and Gubernatoriana pusilla (Roux, 1931) were both transferred to the genus Vanni (Bahir and Yeo 2007; Ng et al. 2008).

Gubernatoriana Bott, 1970, now consists of three species: Gubernatoriana gubernatoris (Alcock 1909), Gubernatoriana pilosipes (Alcock 1909), and Gubernatoriana triangulus sp. nov.

\section{Ecological notes}

These crabs are found in small streams, under small stones in high-altitude areas in Western Ghats of India (Pati and Sharma, unpublished data).

\section{Distribution}

Northern Western Ghat Mountains (Maharashtra: Satara, Pune); Karnataka: NorthCanara (Bott 1970).

Gubernatoriana triangulus sp. nov.

(Figures 6A-C, 7A-H, and 8C)

\section{Type specimens}

Holotype: male (cw $12.52 \mathrm{~mm}$, cl $10.60 \mathrm{~mm}$, ch $6.28 \mathrm{~mm}$, fw $5.22 \mathrm{~mm}$ ), B.S. Lamba (ZSI, WRC-C.1134), Dhobi Waterfall, Mahabaleshwar, Satara district, Maharashtra, 
India, $17^{\circ} 56^{\prime} 8.484^{\prime \prime} \mathrm{N}, 73^{\circ} 38^{\prime} 49.311^{\prime \prime} \mathrm{E}$, alt. $1207 \mathrm{~m}$; paratypes: 1 male (cw $9.00 \mathrm{~mm}$, cl $7.40 \mathrm{~mm}$, ch $4.12 \mathrm{~mm}$, fw $3.54 \mathrm{~mm}$ ), S.K. Pati (ZSI, WRC-C.471), Bhaka Devi and vicinity, Bhimashankar Wildlife Sanctuary, Pune district, Maharashtra, India, $19^{\circ} 5^{\prime}$ 27.729" N, 73'32'7.8246" E, alt. $955 \mathrm{~m}$ and 1 female (cw $9.34 \mathrm{~mm}$, cl $7.24 \mathrm{~mm}$, ch $3.92 \mathrm{~mm}$, fw $3.54 \mathrm{~mm}$ ), S.K. Pati (ZSI, WRC-C.1087), Dongarwadi, Tahmini Ghat, Pune district, Maharashtra, India, 18²9'4.8948" N, 73²4'53.8878" E, alt. 593 m.

\section{Diagnosis}

Carapace squarish (cl/cw $0.76-0.78)$, highly arched anteriorly (ch/cl 0.59), less convex posteriorly; dorsal surface almost smooth; anterolateral margin short, smooth, cristiform; posterolateral margin with fine, oblique striations; frontal margin slightly concave medially; epigastric crests faint, flat, broad; postorbital crests indistinct; epibranchial tooth indistinct; branchial regions inflated; subhepatic region smooth; H-groove faint; frontal median triangle incomplete with only dorsal margin; epistomal median lobe broadly triangular, without median tooth (Figure 6A,B). Suture between thoracic sternites s2/s3 indistinct, suture between sternites s3/s4 absent except for two short lateral grooves (Figures 6C, 7A). Male abdomen short, almost Tshaped; fifth abdominal somite much broader than long; sixth abdominal somite slightly broader than long, equal in length to telson; telson short, broadly triangular (Figure 7B); male sternoabdominal cavity deep, long, extending beyond level of third maxilliped bases (Figure 6C). Exopods of first, second maxillipeds with long flagellum; exopod of third maxilliped lacking flagellum (Figure 7D). G1 short, stout with long terminal article ( 0.5 times length of subterminal segment); terminal article slimmer than subterminal segment, slightly curved outward, tip pointed; subterminal segment almost triangular, basal half broader than distal half (Figure 7E-G). G2 short, terminal article very short (Figure $7 \mathrm{H})$.

\section{Description}

Carapace squarish, highly arched anteriorly (ch/cl 0.59), less convex posteriorly; dorsal surface almost smooth; anterolateral carapace inflated in frontal view; anterolateral margin short, smooth, cristiform; posterolateral margin with fine, oblique striations; front vertically deflexed, flat, square cut, wide (fw/cw 0.4); frontal margin slightly concave medially; epigastric crests faint, flat, broad; postorbital crests indistinct; external orbital angle poorly developed; epibranchial tooth indistinct; postorbital region flat; branchial regions inflated considerably; subhepatic region smooth; cervical grooves indistinct; mesogastric groove long, slightly extending into frontal region; H-groove faint; frontal median triangle incomplete with only dorsal margin; epistomal median lobe broadly triangular without median tooth (Figure 6A,B).

Chelipeds smooth, unequal; few small blunt teeth on anterior margin of major (left) chela; large gape between fingers of larger chela when tips in contact (Figure 7C); fingers slightly shorter than palm; teeth on fingers of smaller chela small, blunt; carpal spine poorly developed, blunt; outer surface of merus rugose.

Ambulatory legs (p2-p5) long with bristles on margins of carpus, propodus, and dactylus; dactylus (p4 and p5) equal in length to propodus; longest propodus (p3) almost three times as long as broad. 
Suture between thoracic sternites $\mathrm{s} 2 / \mathrm{s} 3$ indistinct, suture between sternites $\mathrm{s} 3 / \mathrm{s} 4$ absent except for two short deep lateral grooves (Figures 6C, 7A).

Male abdomen short, almost T-shaped; fifth abdominal somite broader than long, lateral margins not parallel to each other; sixth abdominal somite broader than long, equal in length to telson, lateral margins convex; telson broadly triangular, length equal to proximal width (Figure 7B); male sternoabdominal cavity deep, long, extending beyond level of third maxilliped bases (Figure 6C).

Exopods of first, second maxillipeds with long flagellum; exopod of third maxilliped lacking flagellum, longer than ischium; ventral sulcus on ischium indistinct, anterior external angle of merus right angled, depression on merus towards inner sides (Figure 7D). Mandibular palp with two joints, terminal joint bilobed.

G1 short, stout with long terminal article $(0.5$ times length of subterminal segment); terminal article slimmer than subterminal segment, slightly curved outward, tip pointed; subterminal segment almost triangular, basal half distinctly broader than distal half (Figure 7E-G). G2 short with very short terminal article; proximal half of basal segment stout, broader than distal half (Figure $7 \mathrm{H})$.

\section{Colour}

Live crabs have a brown carapace, and yellowish brown chelipeds and ambulatory legs (Figure 8C).

\section{Etymology}

In Latin triangulus means triangular, referring to the triangular shape of the G1 subterminal segment. Used as noun in apposition.

\section{Remarks}

Gubernatoriana triangulus sp. nov. is similar to both G. gubernatoris and G. pilosipes in carapace morphology. Differences between these three taxa include the carapace height, which in G. triangulus is more inflated in the branchial regions than in the other two species, a smooth subhepatic region in $G$. triangulus (vs a rugose subhepatic region), a male sternoabdominal cavity extending beyond the level of the third maxilliped bases in G. triangulus (vs a male sternoabdominal cavity not extending beyond the level of cheliped bases) (Figure 6A,C; Bott 1970: pl. 6, figs. 61, 62; pl. 34, figs. 33, 34). The G1 subterminal segment of G. triangulus is triangular in appearance i.e. basal half distinctly stouter than distal half (vs basal one-third slightly broader than distal two-thirds in G. gubernatoris and basal two-thirds slightly broader than distal one-third in G. pilosipes) (Figure 7E,F; Bott 1970: pl. 27, fig. 27; pl. 34, fig. 36).

\section{Ecological notes}

Specimens were found in the Western Ghat Mountains, India, along the small stream banks, in small water bodies, and under small stones. This species is very active especially during the rainy season (from June to September) (Pati and Sharma, unpublished data). 


\section{Distribution}

Northern Western Ghats (Satara and Pune).

\section{Key to the species of Gubernatoriana}

1. Branchial regions inflated (ch/cl 0.59); subhepatic region smooth. Male sternoabdominal cavity long, extending beyond level of third maxilliped bases. G1 subterminal segment stout, triangular

Gubernatoriana triangulus sp. nov. Branchial regions not inflated (ch/cl $0.48-0.58)$; subhepatic region rugose. Male sternoabdominal cavity short, extending to level of cheliped bases. G1 subterminal segment slim, not triangular

2. Suture between thoracic sternites 2 and 3 indistinct. Tips of fingers of major cheliped pointed. G1 terminal article long ( 0.45 times length of subterminal segment); basal third of subterminal segment broader than distal two-thirds Gubernatoriana gubernatoris (Alcock, 1909) Suture between thoracic sternites 2 and 3 visible, complete groove. Tips of fingers of major cheliped broadly rounded or spoon shaped. G1 terminal article short (0.35 times length of subterminal segment); basal two-thirds of subterminal segment broader than distal third

Gubernatoriana pilosipes (Alcock, 1909)

\section{Acknowledgements}

We are thankful to Dr K. Venkataraman, the Director of Zoological Survey of India, Kolkata for kind support and encouragement. Thanks to the authorities of Maharashtra Forest Department for permission to conduct surveys and for providing information regarding the crabs. Special thanks to Dr M.K. Dev Roy and Mr S. Mitra of Crustacea Section, Zoological Survey of India, Kolkata for facilitating access to the comparative materials under their care. We are thankful to the reviewers for valuable suggestions and comments on the manuscript.

\section{References}

Alcock A. 1909. Diagnoses of new species and varieties of freshwater crabs. No.4. Rec Indian Mus. 3:375-381.

Alcock A. 1910. Brachyura I. Fasc. II. The Indian freshwater crabs-Potamonidae. Catalogue of the Indian Decapod Crustacea in the Collection of the Indian Museum. Calcutta: 1-135, pls.1-14.

Bahir MM, Yeo DCJ. 2007. The gecarcinucid freshwater crabs of southern India (Crustacea: Decapoda: Brachyura). Raffles Bull Zool. Suppl. No. 16:309-354.

Bott R. 1970. Die Süsswasserkrabben von Europa, Asien, Australien und ihre Stammesgeschichte. Eine Revision der Potamoidea und der Parathelphusoidea (Crustacea, Decapoda). Abh Senckenb Naturforsch Ges (Frankfurt). 526:1-338. pls. 1-58.

Ng PKL, Guinot D, Davie PFJ. 2008. Systema Brachyurorum: Part I. An annotated checklist of extant brachyuran crabs of the world. Raffles Bull Zool. 17:1-286.

Ng PKL, Tay FWM. 2001. The freshwater crabs of Sri Lanka (Decapoda: Brachyura: Parathelphusidae). Zeylanica. 6:113-199.

Rathbun MJ. 1904. Les crabs d'eau douce. Nouv Arch Mus Hist Nat Paris Series 4. 6:225-312.

Roux J. 1931. Crustacés Décapodes d'eau douce de l'Inde méridionale. Rev Suisse Zool. $38: 31-62$. 